\title{
Institutional ethnography: A sociology for librarianship
}

\author{
Nicole K Dalmer, Roz Stooke, Pam McKenzie
}

\begin{abstract}
Canadian sociologist Dorothy Smith's institutional ethnography (IE) is an ontology of the social that conceptualises 'life as usual' as the ongoing coordination of people's actions across diverse sites. Popular in the health sciences and human service professions as a research strategy for understanding and explicating problematics of everyday life, it is slowly gaining traction as a critical research approach for library and information science (LIS). This article introduces IE and provides an overview of its central tenets. It outlines ways in which institutional ethnographers identify research problematics and collect and analyse data. The article concludes with three illustrations of how institutional ethnography has been used to map the linkages among activities and institutional processes, ultimately revealing how it can contribute to a critical understanding of library and information science practices and scholarship.
\end{abstract}

\section{Introduction}

In the years since Wayne Wiegand drew the library and information science (LIS) community's attention to "tunnel vision and blind spots" (1999, p. 3) in LIS discourses, an increasing number of LIS scholars have adopted critically-oriented approaches to research with the result that there now exists a robust community of critical researchers and activists (see, for example, the critlib.org website and the recent publication of the inaugural issue of the Journal of Critical Library and

\section{Authors}

Nicole Dalmer is a doctoral candidate in the Library and Information Science program at The University of Western Ontario where she researches the intersections of aging, care, and information work.

Email: ndalmer@uwo.ca

Roz Stooke is a former children's librarian who teaches in the Faculty of Education at The University of Western Ontario where she promotes IE as a form of critical praxis.

Email: rstooke@uwo.ca

Pam McKenzie researches the everyday and teaches in the Faculty of Information and Media Studies at The University of Western Ontario.

Email:pmckenzi@uwo.ca

Received 2 February 2017

Accepted 11 May 2017 
Information Studies). In this article, we describe a critically oriented approach to research called Institutional Ethnography (IE) and demonstrate how it can contribute to a critical understanding of library and information science practices and scholarship. IE was developed in Canada by the feminist social theorist Dorothy E. Smith $(1987,1990,2005,2006)$ as a response to her own concerns about tunnel vision and blinds spots in sociological research. Smith questioned the widely accepted practice of construing informants as subjects and fitting "the actualities of peoples' lives into theoretical frameworks" (Stooke, 2010, p. 284). She argued instead that people are expert practitioners of social life and can participate in research as expert informants whose accounts of what they routinely do in a setting provide clues to understanding how "life as usual" is produced in that setting. She proposed that an individual's actions in a local setting are always coordinated with the actions of others, both in that local setting and beyond it. She noted, however, that it is difficult for anyone to see the entire web of coordination from one spot. Smith was therefore motivated to create a "way of seeing, from where we actually live, into the powers, processes, and relations that organize and determine the everyday context of that seeing" (Smith, 1987, p. 9).

IE lends itself to collaboration between activists and academics and has also been taught to graduate students in human service professions such as nursing, social work, and education. Within LIS, Smith's keynote address at the 2007 Library Research Seminar IV was well received and IE studies are slowly gaining prominence: for example studies of librarians' work (Crispin, 2011; Johnston and Santos Green, 2014; Santos Green and Johnston, 2015; Stooke, 2004), studies of evidence-based practice (Pilerot, 2016), studies of information practices and documentation (McKenzie, 2006), studies of children's programs in public libraries (McKenzie and Stooke, 2007; Stooke and McKenzie, 2009), and most recently, a study of the information work embedded in eldercare work (Dalmer, 2016a).

We argue that IE has much to offer critical scholarship in LIS. In the first place, it can support the development of user-centred services and procedures. It affords ways to systematically study and critically examine information work carried out by people whose life circumstances require them to navigate large, complex systems such as the healthcare, social welfare, education or legal systems. It acknowledges too that people's interactions with systems necessitate activities that are not formally recognised as work (for example in workplace documentation, such as Bowker and Star (1999)), yet they are done deliberately and with time and effort and should be understood as work (Smith, 2005, p. 151). Consider, for example, the process of filing a claim for refugee status in Canada (see Bisaillon, 2013). In the second place, IE affords a means of systematically studying work carried out by people whose mandated work roles include mediating large, complex systems on behalf of or prompted by patrons, clients, patients, students, and so on. Information professionals routinely engage in this kind of mediating work, but here too, some aspects of the work are recognised as work and other important aspects go unnoticed. By bringing visibility to work that is often overlooked, IE investigations can serve an emancipatory function. Importantly, IE investigations do not simply document the work; they bring into view "mechanisms of managerial control" (DeVault \& McCoy, 2002, p. 26) and 
ways in which "knowledge and power come together . . . to organize what happens to people" (Campbell \& Gregor, 2002, p. 12).

In the sections that follow, we provide an overview of IE's ontological and epistemological grounding and describe its key concepts. We then discuss the practicalities of conducting an IE study. We identify some sources of data used in IE, highlighting the importance of informants' accounts of their everyday experiences and the mediating roles played by texts and discourses. We then describe some ways to map the linkages between everyday activities and institutional work processes. Finally, we show how the creation of such maps can contribute to a better understanding of library scholars' and practitioners' everyday practices.

\section{Institutional ethnography: A mode of inquiry}

IE is sometimes described as a practice rather than a research approach (for example Smith, 2006). As such, it has been successfully employed as a strategy for critically examining practices in organizations and informal social settings. Its products are not theories, but instead the identification of ruling relations that aim to illuminate the workings of one area of an institutional landscape from the standpoint of an individual or group whose experiences or concerns prompted the inquiry. In this article, however, we focus on IE as an approach for formal research projects.

We begin by noting that although the products of IE inquiries are not theories, the practice of IE is informed by an ensemble of sophisticated ontological and epistemological assumptions. As a graduate student, Smith studied with the interpretive sociologist, Erving Goffman. She was familiar with and profoundly influenced by phenomenology and social interactionism and she shared with ethnomethodologists a desire to understand how people accomplish social life in local settings. Smith uses Garfinkel's social ontology to construct her notion of "the social" and also draws on the analytic power of ethnomethodology to document the effects of social inequality but "to understand the processes that produce them" (Fenstermaker \& West, 2002, p. 96). She was also influenced by her involvement in the Women's Movement and identified a disjuncture between the disembodied modes of thinking that characterised academic life in the 1960s and 1970s and the embodied particularities of her everyday life as a wife and mother of young children. Awareness of this disjuncture drew her back to the writing of Marx and Engels, most notably The German Ideology (1976) in search of "a method of inquiry other than those ... which replicated the objectifying androcentricism of the ruling relations" (Smith, 2004, p. 445).

Smith (2007b) lists five key components of an IE inquiry: first, IE begins in the everyday (and every night) lives and experiences of people; second, it takes on and privileges the standpoint of those whose experiences are under investigation; third, while connected to those everyday experiences, IE simultaneously explores the broader institutional arrangements and relations that coordinate and organise the experiences; fourth, IE examines the roles played by discourses and texts as they are taken up by people; and finally, it creates maps for individuals to 
understand and trace how their everyday lives, experiences and activities are organised by institutional arrangements.

\subsection{Assumptions of institutional ethnography}

In this section we describe several key tenets of institutional ethnography.

\subsubsection{Establishing the problematic}

An inquiry begins by locating a puzzle or, in Smith's terms, a "problematic," that is "latent in the actualities of the everyday world" (Smith, 1987, p. 91). As Stooke observes:

In many settings, but especially in human services settings, it is not uncommon for a study to be developed in response to a vague but nagging and persistent concern about a situation whose determinants seem to elude those people most affected by the situation

(Stooke, 2010, p. 289). Starting from individual accounts of everyday experiences allows the researcher to identify a "problematic of the everyday world," that is, "a possible set of questions that are 'latent' in the actualities of the experienced world" (Smith 1987, p. 91). Locating the problematic prompts a researcher to ask: what is the work and how is this work organised? In locating the problematic for her ongoing doctoral work, Dalmer (2016a) was struck by the increasing amounts of carerelated information available to family caregivers of older adults, yet the continued reports of caregivers' frustrations with finding and using this information. Beginning in the actualities of family caregivers' everyday (and every night) lives enabled a questioning of the everyday work needed to use, find and make sense of the information needed to provide care to a family member living with dementia. Articulating this problematic organised the direction of her overall IE investigation from the standpoint of those caregivers whose work was the study's starting point. Following the caregiver's information work that supports an older adult's ability to age in place made visible how the informationrelated care work that caregivers of community-dwelling older adults living with dementia perform is hooked into ruling relations emanating from aging in place policies and administration.

\subsubsection{Conceptualising work}

Central to IE is its generous conceptualisation of work. IE understands "life as usual" to be constituted by work, which includes the "ongoing concerting and coordinating of individuals' activities" (Smith, 1999, p. 7) or in other words, "anything done by people that takes time and effort, that they mean to do, that is done under definite conditions and with whatever means and tools, and that they may have to think about" (Smith, 2005, p. 151). This conceptualisation treats a host of unpaid activities as work and is evocative of the argument put forward in the 1970s by feminists bringing attention to the network of unpaid and often invisible work performed by women in the house or, indeed, by public service 
librarians (Stooke, 2004). Smith's concept of work knowledge, “a person's experience of and in their own work, what they do, how they do it, including what they think and feel" (Smith, 2005, p. 151), orients the researcher to consider informants as experts about their own work. An institutional ethnography therefore always begins at the local level, with people's everyday work and experiences (Griffith \& Smith, 2005). Starting in the local actualities of the everyday world enables IE to be "a sociology for people" and illuminates the invisible (owing, in part to its commonplace in the everyday) work done, for example, by information professionals and patrons, to be brought into view and available for critical examination.

\subsubsection{Ruling relations}

The social organization of our everyday lives, however, cannot be fully understood by lingering at the local level. Therefore, while IE regards the experience of daily life as a starting point, the inquiry must go further in order to:

penetrate into the social relations that organize what is ordinarily conceived as the systemic or macrolevel of the social, from the standpoint of people whose activities produce, reproduce and change them, and to locate those relations beyond people's experience as they enter into and organize their lives and work.

(Griffith \& Smith, 2005, p. 3)

IE therefore moves outwards from local, everyday experiences and knowledge, searching for and making known the networked linkages of organization and coordination that are external to those informants whose everyday work is under study, but that still shape their local experiences. Smith calls these invisible, networked linkages ruling relations. An integral concept in IE, ruling relations create and contain power in societies, coordinating people's everyday activities in and across multiple locations and across time, including the activities of people who may not be known to each other. Large corporations, government bureaucracies, processes of administration and governance, academic and professional discourses, and mass media are all manifestations of ruling relations. A chief goal of IE investigations is to make ruling relations visible to reveal the practices and discourses that coordinate people's activities across time and space.

\subsubsection{Social organization of knowledge}

Smith challenged traditional sociological thinking by proposing that sociology ought to produce knowledge about people rather than for them (Stooke, 2010). Permeating IE is its firm stance that knowledge is socially organised, socially constructed, and socially situated (Smith, 1990). Smith critiques objectified forms of knowledge, arguing that "its characteristic textual forms bear and replicate social relations" (Smith, 2005, p. 27). She calls instead for the need to expose the social organization of ruling relations that create and preserve taken-for-granted forms of knowledge and power (Mann \& Kelly, 1997). As such, IE is a method of inquiry into the social, grounded in the everyday, with an aim to "reorganize the social relations of knowledge of the social so that people can take that knowledge up as an extension of our ordinary knowledge of the local actualities of our lives" (Smith, 2005, p. 29). 


\section{Conducting an institutional ethnography inquiry}

One immutable aspect of an IE study is its standpoint. An IE study explores ruling relations as they are encountered by people whose experiences are under study, and it maintains that standpoint throughout. Crispin (2009) took the standpoint of school librarians to understand how social organization influences cooperation with school staff. McKenzie and Dalmer (2016) took the standpoint of family caregivers of older adults to learn about the organization of their informationrelated care work. Given the importance of standpoint for an IE study, participants are called 'informants' as they inform institutional ethnographers about how they do their everyday work.

The difficulty in detailing and planning the methods to be used in an IE study stems not only from the fact that there is "no 'one way' to conduct an IE investigation" (DeVault \& McCoy, 2002, p. 755), but also from the discoveryladen nature of this method of inquiry. Indeed, an IE analysis begins in the planning stages of the inquiry and data collection methods are guided by what is discovered at each stage, constraining the institutional ethnographer's ability to specify beforehand exactly what steps she will take. DeVault and McCoy (2002, p. 755) beautifully summarise this process:

The process of inquiry is rather like grabbing a ball of string, finding a thread, and then pulling it out; that is why it is difficult to specify in advance exactly what the research will consist of. The researcher knows what she wants to explain, but only step by step does she know who she needs to interview, or what texts and discourses she needs to examine.

(DeVault \& McCoy, 2002, p. 755)

As DeVault and McCoy make clear, each step of an IE inquiry must systematically build on what has already been discovered, pushing deeper into the process of making ruling relations visible. An IE inquiry grows recursively and abductively, and "pushes beyond the local settings of people's everyday experience, and it must do so by finding those extended relations that coordinate multiple settings translocally" (Smith, 2005, p. 49). Rather than suggesting a formulaic recipe, DeVault and McCoy (2002, p. 755) list three broad processes that an IE study should accomplish: (a) identify an experience that represents or constitutes the problematic, (b) identify the institutional processes that may be shaping or organising the experience, and (c) explore the processes in order to uncover how they influence and mitigate the experience under investigation.

\subsection{Two types of data}

This movement from the local, everyday world of informants to the external, invisible ruling relations that mould the experience of the local requires the researcher to collect data at two different levels. Entry-level data focuses on an informant's every day, enabling the researcher to locate an opening into the problematic of the everyday world. From entry-level data, an IE inquiry must move to collecting level two data, that is, data that is "positioned outside the 
setting" (Deveau, 2008, p. 15) that allow the institutional ethnographer to work back to see how the experiences collected in the entry-level data happened as they did. It is this level two data that make the ruling relations of the everyday experience explicable as they reveal "how people's everyday lives may be organized without their explicit awareness but still with their active involvement" (Campbell and Gregor, 2004, p. 43) and enable one to see how "people and events are tied together in ways that will make sense of such abstractions as power, knowledge, capitalism, patriarchy, race, the economy, the state, policy, culture, etc." (Campbell \& Gregor, 2004, p. 17). The inquiry can thus begin to go beyond the work knowledges of informants in any local setting to map the ruling relations that influence the experiences described in the entry-level data. For example, Stooke (2004) observed the everyday work of children's librarians (entry-level data) which led her to observe the gendered nature of that work, uncovering mechanisms by which it is being coordinated by American educational reforms and OECD policies for early child development (level two data).

\subsection{Data collection}

There is no one 'type' of institutional ethnography study and because of this, data collection may assume a variety of forms. As an institutional ethnography study necessitates an examination of how activities (work) across multiple locations are coordinated (Campbell \& Gregor, 2004), IE studies typically use a variety of methods to collect data from and about their informants. Each of the methods are selected in an attempt to capture the many forms in which ruling relations may be present in and working on individuals' everyday lives.

There is likewise no prescribed "sample size" in an IE study. The IE researcher follows the experiences and hints revealed in entry-level data and continues to collect and analyse level two data (texts, interviews or observations) until she develops a comprehensive understanding of the ruling relations present (Prodinger, 2012). She places priority on engaging with texts or individuals "who participate in such a regime to explore with them the work they are doing and to make visible in this way how the institutional regime enters into the organization of that work" (Griffith \& Smith, 2005, p. 4). Data collection therefore continues until the the researcher has exposed a network of links between entry-level and level two data. In this way, as further elaborated in section 3.3, data analysis occurs throughout data collection.

\subsubsection{Collecting entry-level data}

As noted above, interviews often serve as the entry-level data of an institutional ethnography study and are framed as "talking with people" about their everyday work (DeVault \& McCoy, 2002, p. 384). Grounded in Smith's concept of work knowledge, (Smith, 2005, p. 151), interviews are rooted in everyday routines and place expertise in the hands of informants.

Each interview, whether one-on-one or in a focus group, is conducted with the acknowledgement that every informant participates, knowingly or unknowingly, in ruling relations that shape their experiences. Informants' accounts, stories, and 
descriptions are used to identify some of the institutional processes, discourses, and overarching ruling relations that shape those local experiences. To tease out ways in which descriptions of everyday work are embedded in ruling relations, a researcher may ask informants to talk about a typical day. The researcher, then, is tasked with posing questions that chip away at institutionally embedded language to understand the many processes and structures that may intersect with and coordinate that everyday work.

\subsubsection{Collecting level two data}

As she learns about these processes and structures, the researcher may shift to interviewing people outside of the local setting (level two data) to understand the ruling relations that shape the experiences under study but that may be unknown to the entry-level informants. As Campbell and Gregor explain, "to understand the workings of any setting involves learning how people, seemingly positioned outside the setting, are nevertheless active inside it" (2002, p. 60). For example, a parent's ability to take a child to the public library may be shaped by decisions made by city planners around public transit schedules and zoning for parking. Frontline workers in organizational and professional work sites are key sources of data in an IE study as they are tasked with understanding and working with "the categories and protocols of a professional regime" (DeVault \& McCoy, 2002, p. 760).

Entry-level interviews may likewise reveal sequences of action in which specific texts are implicated. Such texts may be studied as level two data to show how they organise and coordinate people's activities across time and place (Smith, 2006). Smith speaks of texts as "words, images, or sounds that are set into a material form of some kind from which they can be read, seen, heard, watched, and so on" (Smith, 2006, p. 66) and include paintings, music, television and writing. Two key elements of texts facilitate their utility as level two data and enable researchers to go beyond an individual's everyday experiences to reveal ruling relations: the replicability of texts and their ability to be read or heard by any number of individuals in identical form across time and space (Smith, 2005).

Smith's term, "textually-mediated social organization" is in recognition that texts coordinate the actions of people. Of importance here is that these texts can organise informants' experiences and work even if not directly engaging with them. Dalmer (2016b), for example, conducted a scoping review of eldercarerelated scholarly literature to examine how academic texts take up and shape how caregivers' information-related care work is conceptualised, researched and reported. Of particular importance, in an IE study, is that texts are not examined for their factual information or content but instead for evidence of "crystallized social relations" (Campbell \& Gregor, 2004, p. 9). Texts (which in a library setting could include library policies, action plans, organizational guidelines, forms that library patrons fill out, signs posted around a library space, etc.) are examined for their role in structuring informants' experiences. For example, a children's storytime is organised by the texts of canonical children's literature, such as English-language nursery rhymes, as well as by professional texts that discuss children's librarians' roles and responsibilities with respect to early literacy research (Stooke \& McKenzie, 2011). 


\subsection{Analysis}

Analysis is not a discrete or sequential step in an IE investigation, but instead takes place throughout the entire trajectory of an IE study, from the identification of the problematic to the mapping of the ruling relations and their coordination of everyday activities. Stooke (2010) outlines two objectives when analysing data collected in an institutional ethnography: the first is to learn about the problematic under investigation and the second is to identify those institutional processes and ruling relations that are present in the coordination and organization of the experiences.

\subsubsection{Analysing entry-level data}

In interviews, the analytic process begins during the data collection period, as the researcher continually checks and verifies her evolving understanding with the informant. The loose structuring of interviews is helpful in the analysis process as "the story of their work is essential to the analysis that defines the problematic" (Smith, 1987, p. 187). DeVault (1999) observes that entry-level informants may feel unsure about how to see or speak about their experiences apart from the ways those experiences are interpreted and constructed by prevailing organizations and norms. The researcher therefore needs to listen carefully for clues that point to ruling relations active in their accounts. Points of disjuncture in informants' accounts may illuminate differences in "knowing something from a ruling versus an experiential perspective" (Campbell \& Gregor, 2004, p. 48). In Stooke's interviews with children's librarians, there was a disjuncture between the librarians' desire to be seen as literacy experts and the need to maintain high attendance at programs. For example, one librarian described how important it was for librarians to claim expertise "under our own umbrella," yet she also recalled that her mentor had said "The most important thing you tell a mother is that her child is beautiful." Notably, the analysis always makes use of informants' own words and what informants know (that is, their work knowledges).

Ruling relations are held as the analytic anchor throughout the analysis process. The key query to guide the analysis is: "What does it tell me about how this setting or event happens as it does?" (Campbell and Gregor, 2004, 85). To keep the ruling relations central to the analysis process, institutional ethnographers do not divide interview transcripts into themes, chunks or other sorted categories. Furthermore, a successful IE analysis refuses any single view or narrative and "supersedes any one account and even supersedes the totality of what informants know and can tell" (Campbell \& Gregor, 2004, p. 85). Understanding and analysing data is contingent on unearthing and explicating how ruling relations come to be and how they coordinate and organise informants' experiences and work across diverse settings (Campbell \& Gregor, 2004). As a result, producing accounts of and from informants' work knowledges is useful, but an IE analysis requires a researcher to trace the entry-level informant's individual experience beyond their local setting to reveal the larger frame of reference and the ruling relations at play.

\subsubsection{Analysing level two data}


The goal of analysing level two data, whether data coming from texts or from interviews, is to reveal how everyday life happens as it does (Campbell and Gregor, 2004), working back to see how informants' experiences happened as they did. The analysis uncovers how informants' work is organised outside their own knowledge and coordination, and ultimately produces a map. The construction of a map is used as a technique to depict the network of ruling relations that connect one local site to another and helps to determine how these ruling relations impact people's everyday work in their local environments. From Stooke's (2004) research that examined the intricacies of children's librarians work to support young children's education and development, Figure 1 provides an example of a map produced over the course of an IE study. This map allows the researcher to 'see beyond the local' and depicts the interconnected ruling relations between individuals, agencies, policies, and texts (among others) that operate translocally but that coordinate the everyday, local work of children's librarians.



Figure 1. Mapping the social organization of children librarians' work

Crucial in this analytic process is how the researcher treats informants' work knowledges. The importance of work knowledges lies is the direction of inquiry that they propose, that is, the "sequences of action in which [the work knowledge] is embedded and which implicate other people, other experience, and other work in the institutional process on which research is focused" (Smith, 2005, p. 158). The researcher may analyse level two interviews in the manner described in section 3.3.1. In order to keep the analytical focus on the organization of the entry-level informant's experience, texts can be analysed for their approach to and acknowledgement of the informant's experiences and work (or lack thereof), by 
examining texts' use of language (and power), organisational interests, and any indications of unstated assumptions.

Regardless of data type, the researcher's challenge in analysing data in an institutional ethnography is maintaining the analytic focus and interest on the informants (and their work knowledges) while simultaneously seeing where and how ruling relations coordinate informants' experiences (Campbell \& Gregor, 2004). While rigor in positivist studies is often assessed by validity and reliability, rigor in an IE investigation stems from its design and method (Townsend, 1998). More specifically, throughout the analysis process, the institutional ethnographer is accurate to what actually happens, keeping descriptions of informants' everyday lives and the mapping of the ruling relations that shape local experiences transparent and comprehensive (Prodinger, 2012; Rankin \& Campbell, 2006). The researcher maintains reflexivity by constantly asking informants what they mean and by asking 'what happened next?' when asking about their everyday work. Trustworthiness of the data in an IE study stems from the researchers' faithfulness and closeness, not to the researchers' interpretations, but to the concrete descriptions and tellings of informants' accounts.

\section{Institutional ethnography as praxis: Explicating library and information science work}

To this point, this article has described institutional ethnography as a method of inquiry. In this section we highlight its relevance to LIS, particularly the ways in which it can disrupt "tunnel vision and blind spots" (Wiegand, 1999, p. 3) that undermine the field's democratic and social justice goals. One way to make visible the blind spots in our practice, whether as librarians, information professionals or as researchers, is to show how practices are embedded in and shaped by ruling relations. To this end, the authors each speak about ways that IE has supported their own research.

As noted above, institutional ethnography can be employed as a systematic mode of inquiry or an informal strategy for looking at everyday practice. As an informal strategy, institutional ethnography may inform teaching in professional programmes. Nurse educators Campbell and Gregor (2002, 2004), for example, teach IE strategies to graduate students as a complement to reflective practice (Schön, 1987) and Stooke has taught the strategy of 'looking beyond the local' to students in a graduate course entitled 'Understanding the Early Childhood Educator'. As in reflective practice, IE explorations focus first on work that seems to be implicated in the construction or maintenance of a troubling situation. However, where reflective practice requires practitioners to look inward at their emotional responses to situations and to tease out beliefs and assumptions that seem to be driving their actions, IE aims to uncover the texts and associated work processes that connect local practices to work being done in other settings. In this way, IE can complement a reflective practice and mitigate the tendency for early childhood education (ECE) practitioners to blame themselves for problematic situations. Stooke invites students to find a problematic in their own professional experiences and to map linkages with other kinds of institutional work. Many of 
the students have been surprised to discover how their practices are being aligned with policies recommended in reports produced by transnational, nongovernmental organizations such as the OECD and several students have been motivated to map processes by which recent policies aimed at professionalizing the ECE workforce are actually limiting their opportunities for career advancement. The students have then used their maps to navigate ways around the obstacles.

In her ongoing doctoral work, Dalmer (2016b, 2016c) uses institutional ethnography to map out the complex relationship between information and care by tracing the processes through which family caregivers' information work falls out of view as work. IE allows her to consider caregivers' everyday information practices as 'work', to examine the multiple institutions and individuals involved in the care work of older adults, and to explore the intricate ways in which lived, everyday informational experiences of caregivers are changed by or fit within current understandings and attitudes towards aging in place. To begin unraveling the ruling relations emanating from an aging in place institutional complex (a government mandate that encourages older adults to live at home for as long as possible), four interconnected studies uncover links between the institutions and individuals that shape, organise, and contribute to the invisibility of caregivers' information work. Interviews with family caregivers of older adults articulate and make visible their information work and interviews with paid senior service providers uncover how seniors' organizations determine how and when to deliver information to families about the aging process. Complementing the everyday experiences from interviews with entry-level (family caregivers) and level two (paid senior service providers) informants, two text-based studies illuminate the role of discourse in coordinating family caregivers' information work: a scoping review of existing literature on caregivers' information practices and an analysis of aging in place policy documents collectively reveal how the nature of texts can perpetuate the invisibility of caregivers' information work.

IE researchers can illuminate some hitherto unacknowledged aspects of library and information work, relations organizing the work, and ways in which librarians' actions make a difference to the lives of library patrons and others. In her doctoral research, Stooke (2004) explicated linkages between the hotly contested No Child Left Behind (NCLB) educational reforms in the United States and public library advocacy activities in Canada. She concluded that by aligning library services for young children with practices recommended by the American Library Association (ALA), the librarians who participated in her study were able to argue that their services were based on scientifically-based reading research and were therefore educationally relevant. Following further research in communitybased early learning programs, Stooke and McKenzie (2011) argued that the library community's emphasis on scientifically-based reading research referenced a narrow definition of research as well as a narrow definition of literacy. They proposed that in framing research narrowly, the public library community was undermining its ability to address longstanding ethical imperatives such as inclusive services. They proposed too that framing literacy narrowly could well be undermining the public library's relevance and contributions to twenty-first century literacies. Importantly, they contended that the narrow definition of 
literacy put forth in scientifically-based studies of reading research positions children's librarians as relatively unskilled teachers' assistants rather than literacy educators in their own right. Finally, they employed IE to argue that events and activities woven into the fabric of everyday life attract too little attention from policy makers (Stooke and McKenzie, 2010). Librarians should therefore resist the temptation to smooth over the 'small stuff' and engage in research that shows how 'small stuff' enhances library users' satisfaction and engagement.

\section{Conclusion}

This article provided an introduction to institutional ethnography with a view to promoting its use in library and information science practice and research. Its starting point in the everyday and its generous conceptualisation of work make IE uniquely situated to bring attention to taken-for-granted aspects of informationand library-related work and to highlight the ways in which textually-mediated work processes draw library and information practices into relations of ruling. IE presents itself as an approach that simultaneously studies the local and extralocal organisation of people's experiences. By exploring and mapping how the information experiences of individuals are embedded in work being carried out elsewhere and at other times, institutional ethnography can contribute to a better understanding of the nuances of library researchers', practitioners' and patrons' everyday practices.

\section{References}

Bisaillon, L. (2013). Disease, disparities and decision making: Mandatory HIV testing of prospective immigrants to Canada. BioéthiqueOnline, 2(10), 1-6.

Bowker, G. C., \& Star, S. L. (1999). What a difference a name makes - the classification of nursing work. In G. C. Bowker, G. C \& S. L. Star, Sorting things out: Classification and its consequences (pp. 229-254). Cambridge, Massachusetts: MIT Press.

Campbell, M. (2006). Institutional ethnography and experience as data. In D. E. Smith (Ed.), Institutional ethnography as practice (pp. 91-108). New York: Rowman and Littlefield Publishers.

Campbell, M., \& Gregor, F. (2002). Mapping social relations: a primer in doing institutional ethnography. Toronto: University of Toronto Press.

Campbell, M., \& Gregor, F., (2004). Theory ‘in’ everyday life. In W. K. Carroll, (Ed.), Critical strategies for social research (pp. 170-180). Toronto: Canadian Scholars Press.

Crispin, J. (2009). Discovering the social organization of school library work. $\mathrm{PhD}$ dissertation, University of Missouri, Columbia.

Crispin, J. (2011). Stumbling around: Towards an approach to institutional ethnography as a frame of inquiry into library work. In McKenzie, P., Johnson, C., and Stevenson, S. (eds.), Exploring interactions of people, places and information: proceedings from CAIS the annual conference of CAIS/actes $d u$ congrès annuel de l'ACSI. Retrieved from http://www.caisacsi.ca/ojs/index.php/cais/article/view/256/12 
Dalmer, N. (2016a). Information as work: Mapping intersections of information work and eldercare', poster presented at: Radical Change: Inclusion and Innovation - Association for Library and Information Science Education, $5^{\text {th }}$ January 2016, Boston, Massachusetts.

Dalmer, N. (2016b). Portrayals of family caregivers' information work: An institutional ethnographic scoping review, paper presented at $5^{\text {th }}$ Biennial Bilingual Conference - Canadian Society for Sociology of Health, $5^{\text {th }}$ May 2016, Ottawa, Ontario.

Dalmer, N. (2016c). Family caregivers' information work made (in)visible: An institutional ethnographic aging in place policy analysis, paper presented at: 45th Annual Scientific and Education Meeting - Canadian Association on Gerontology, 21st October 2016, Montreal, Quebec.

DeVault, M. L. (1999). Liberating method: Feminism and social research. Philadelphia: Temple University Press.

DeVault, M. L., \& McCoy, L. (2002). Institutional ethnography: using interviews to investigate ruling relations. In J. F. Gubrium, and J. A. Holstein (Eds.), Handbook of interview research: Context and method (pp. 751-776). Thousand Oaks, CA: Sage.

Deveau, J. L. (2008). Examining the institutional ethnographer's toolkit. Socialist Studies/Études socialistes, 4(2), 1-19.

Fenstermaker, S., \& West, C. (2002). Doing gender, doing difference: inequality, power, and institutional change. New York: Routledge.

Griffith, A. I. (2006). Constructing single parent families for schooling: discovering an institutional discourse. In D. E. Smith (Ed.), Institutional ethnography as practice (pp. 127-138). New York: Rowman and Littlefield Publishers.

Griffith, A. I., \& Smith, D. E. (2005). Mothering for schooling. New York: Psychology Press.

Johnston, M., \& Santos Green, L. (2014). Innovative partnerships: Exploring school librarianship through a global lens. In M. Griffis, H. Julien, \& L. Given, (Eds.), Connecting Across Borders: Globalization and Information Science Research: Proceedings from CAIS the Annual Conference of CAIS/Actes du congrès annuel de l'ACSI. Retrieved from http://www.caisacsi.ca/ojs/index.php/cais/article/view/894/814

Mann, S. A., \& Kelly, L. R. (1997). Standing at the crossroads of modernist thought: Collins, Smith, and the new feminist epistemologies. Gender \& Society, 11(4), 391-408.

McCoy, L. (2006). Keeping the institution in view: Working with interview accounts of everyday experience. In D. E. Smith, (Ed.), Institutional ethnography as practice (pp. 109-126). New York: Rowman and Littlefield Publishers.

McKenzie, P. J. (2006). Mapping textually mediated information practice in clinical midwifery care. In A. Spink, \& C. Cole (Eds.), New directions in human information behavior. Dordrecht: Springer. 73-92. 
McKenzie, P., \& Dalmer, N. (2016). Creating communities of care: Delineating work in the information-care relationship. In D. H. Michels, \& A Pollak (Eds.), Information science in our communities: Reflections on our work and the people, places and institutions around us: Proceedings of the Annual Conference of cais/Actes du congrès annuel de l'ACSI. Retrieved from https://journals.library.ualberta.ca/ojs.cais-acsi.ca/index.php/caisasci/article/view/939

McKenzie, P. J., \& Stooke, R. K. (2007). Producing storytime: A collectivist analysis of work in a complex communicative space. Library Quarterly, 77(1), 320.

Pilerot, O. (2016). The ruling relation of evidence-based practice: The case of documentary governance in a social welfare service. Information Research 21(1). Retrieved from http://www.informationr.net/ir/211/paper703.html\#.WSQf8RPyvsk

Prodinger, B. (2012). Being an Austrian mother with rheumatoid arthritis: an institutional ethnography about the social organization of everyday life. $\mathrm{PhD}$ dissertation, The University of Western Ontario, London, Canada.

Rankin, J. M., \& Campbell, M. L. (2006). Managing to nurse: Inside Canada's health care reform. Toronto: University of Toronto Press.

Santos Green, L., \& Johnson, M. P. (2015). Global perspectives: Exploring school-based Brazilian librarianship through institutional ethnography. School Libraries Worldwide, 21(1), 1-18.

Schön, D. A. (1987). Educating the reflective practitioner: Toward a new design for teaching and learning in the professions. San Francisco: Jossey-Bass.

Smith, D. E. (1987). The everyday world as problematic: A feminist sociology. Toronto: University of Toronto Press.

Smith, D. E. (1990). The conceptual practices of power: A feminist sociology of knowledge. Toronto: University of Toronto Press.

Smith, D. E. (2005). Institutional ethnography: A sociology for people. Toronto: Altamira Press.

Smith, D. E. (2006). Institutional ethnography as practice. Oxford: Rowman \& Littlefield Publishers.

Smith, D. E. (2007a). Institutional ethnography: Exploring textually-mediated forms of power. Paper presented at Library Research Seminar $I V, 10^{\text {th }}$ October 2007, London, Canada.

Smith, D. E. (2007b) Institutional ethnography: From a sociology for women to a sociology for people. In S. N. Hesse-Biber (Ed.) Handbook of feminist research: Theory and praxis (pp. 409-418). London: SAGE Publications.

Stooke, R. (2004). Healthy, wealthy and ready for school: Supporting young children's education and development in the era of the national children's agenda. PhD dissertation, The University of Western Ontario, London, Canada. 
Stooke, R. (2010). Investigating the textually mediated work of institutions: Dorothy E. Smith's sociology for people. In G. Leckie, L. Given, \& J. E. Buschman (Eds.) Critical theory for library and information science: Exploring the social from across the disciplines (pp. 283-294). Santa Barbara, CA: Libraries Unlimited.

Stooke, R., \& McKenzie, P. J. (2009). Leisure and work in library and community programs for very young children. Library Trends, 57(4), 657-675.

Stooke, R. K., \& McKenzie, P. J. (2010). Attending to the small stuff: Notes from a study of neighbourhood programmes for very young children and their caregivers. Canadian Children, 35(2), 4-9.

Stooke, R. K., \& McKenzie, P. J. (2011). Under our own umbrella: Mobilizing research evidence for early literacy programmes in public libraries. Progressive Librarian, 36/37, 15-29.

Townsend, E. (1998). Good intentions overruled: An institutional ethnography of occupational therapy practices. Toronto: The University of Toronto Press.

Turner, S. M. (2006). Mapping institutions as work and texts. In D. E. Smith (Ed.), Institutional ethnography as practice (pp. 139-161). New York: Rowman and Littlefield Publishers.

Wiegand, W. A. (1999). Tunnel vision and blind spots: What the past tells us about the present: Reflections on the twentieth-century history of American librarianship. The Library Quarterly, 69(1), 1-32.

\section{Open access and copyright}

Library and Information Research is an open access journal. A freely available copy of this paper may be downloaded from the journal's website: http://www.lirgjournal.org.uk/

Copyright and associated moral rights in works published in Library and Information Research are retained by the author(s) but this paper may be used freely, with proper attribution, in educational and other non-commercial settings. 